\title{
A New Non-Uremic Rat Model of Long-Term Peritoneal Dialysis
}

\author{
Y.-M. PENG ${ }^{1 *}$, Z.-J. SHU ${ }^{1,2^{*}}$, L. XIAO ${ }^{1^{*}}$, L. SUN $^{1}$, W.-B. TANG ${ }^{1}$, Y. HUANG ${ }^{1}$, Y.-H. LIU ${ }^{1}$, \\ J. LI ${ }^{1}$, G.-H. LING ${ }^{1}$, X.-Q. XU ${ }^{1}$, U. HALMURAT ${ }^{3}$, F.-Y. LIU ${ }^{1}$ \\ * These authors have contributed equally to this work.
}

${ }^{1}$ Department of Nephrology \& Renal Institute, Second Xiangya Hospital, Central South University, Changsha, Hunan, China, ${ }^{2}$ Department of Nephrology, The Fourth Affiliated Hospital of XinJiang Medical University, Urumuqi, Xinjiang Autonomous Region, China, ${ }^{3}$ XinJiang Medical University, Urumuqi, Xinjiang Autonomous Region, China

Received March 6, 2010

Accepted June 24, 2010

On-line October 15, 2010

\begin{abstract}
Summary
Together with the development of peritoneal dialysis (PD), appropriate animal models play an important role in the investigation of physiological, pathophysiological and clinical aspects of PD. However, there is still not an ideal experimental PD animal model. In this study, 45 Sprague-Dawley rats were divided into three groups. Group $1(n=15)$ was receiving daily peritoneal injection through the catheter connected to the abdominal cavity, using PD solution containing $3.86 \%$ D-glucose. Group 2 ( $n=15)$ was receiving daily peritoneal injection of $0.9 \%$ physiological saline through a catheter. Group $3(n=15)$, which was subjected to sham operation, served as controls. Our results showed that WBC counts in peritoneal effluent of Group 1 were slightly higher than those of Group 2 and control group, respectively $(p<0.05)$. However, there was no episode of infection in any group. In addition, there was no significant difference in neutrophils fractions among these three groups. Hematoxylin-eosin and Masson's trichrome staining demonstrated a dramatic increase in thickness of the mesothelium-to-muscle layer of peritoneum exposed to high glucose (Group 1) compared to Group 2 and controls $(p<0.01)$. These data indicated that we established a novel rat model of PD with a modified catheter insertion method. This model is more practical, easy to operate, not too expensive and it will facilitate the investigate of long-term effects of PD.
\end{abstract}

\section{Key words}

Peritoneal dialysis • Rat model $\bullet$ Dialysis solution $\bullet$ Glucose

\section{Corresponding author}

Fu-you Liu, Department of Nephrology, 2nd Xiangya Hospital, Central South University, No.139 Renmin Middle Road, Changsha, Hunan 410011, China. FAX: 86-731-8529-2064. E-mail: shu5857872@163.com

\section{Introduction}

From a technological point of view peritoneal dialysis (PD) has undergone considerable development over the past 15 years (Teitelbaum et al. 2003). Animal models play an essential role in the research of physiological, pathophysiological and clinical aspects of peritoneal dialysis. An ideal animal model can adequately simulate the process of PD in humans and provide information on the structure and physiology of peritoneal membrane, as well as on the process of peritoneal dialysis, pathophysiology of peritoneal transport, structural changes and local peritoneal defense mechanisms (McIntyre et al. 2007). However, there is still no consensus on the ideal experimental model for studying peritoneal dialysis, especially for long-term peritoneal dialysis (Topley et al. 2005, Gonzalez-Mateo et al. 2008, Mortier et al. 2005).

Recent studies have indicated that there are several factors which affect peritoneum structure, including uremic changes in the internal environment (Plum et al. 2001, Williams et al. 2002, Mortier et al. 2003, Combet et al. 2001), and the bioincompatibility of PD solutions during PD process (Obradovic et al. 2000, 


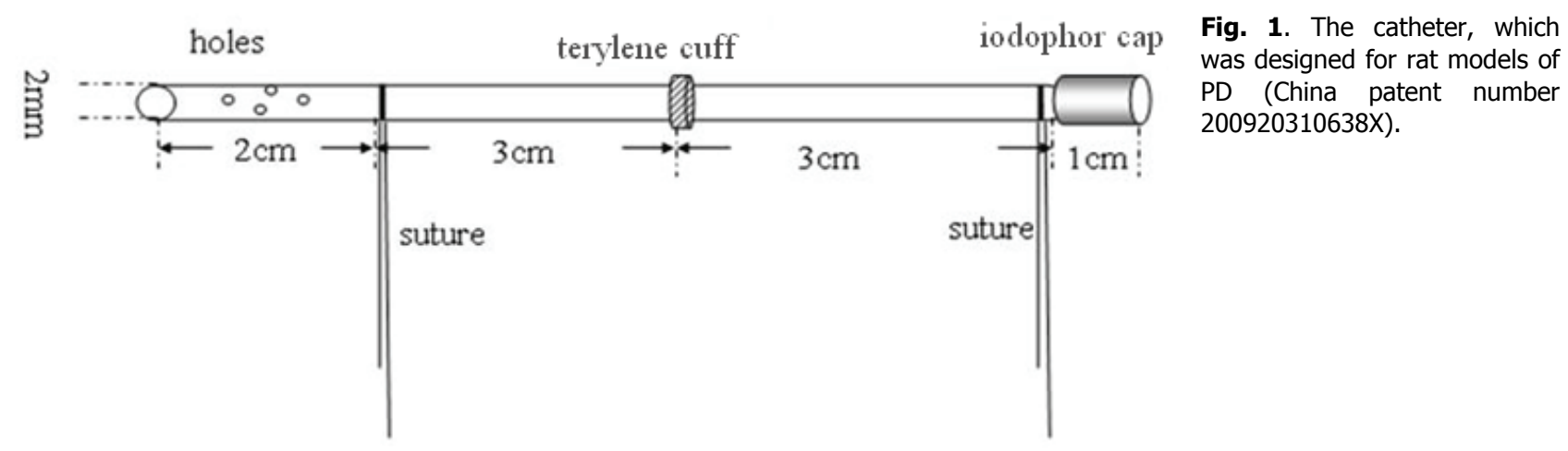

Patent number : $200920310638 \mathrm{X}$

Zareie et al. 2005, De Vriese et al. 2006, Boulanger et al. 2007, Kihm et al. 2008). In addition, there are still some important technical problems, such as catheter obstruction and high incidence of peritonitis, which can cause structural and functional changes of peritoneal barrier in animal models (Mortier et al. 2005, Flessner et al. 2007). To solve these technical problems, we established a novel rat model with a modified catheter insertion method, which would be more practical, easy to operate, not too expensive and which would facilitate the investigation of long-term effects of PD.

\section{Materials and Methods}

\section{Catheters}

The catheter was designed for rat models of PD and had been applied for patent in China (patent number: 200920310638X). The catheter was made by silicone tube, $9 \mathrm{~cm}$ long and $2 \mathrm{~mm}$ in diameter with an iodophor cap on external catheter branch. The iodophor cap can be easily replaced with well. A dacron cuff wrapped the silicone tube and the sutures were fixed on the catheter. There are ten small holes on the intraperitoneal part ( $1 \mathrm{~mm}$ in diameter each) of the tube (Figure 1). The length of catheters can be adjusted according to rat's weight.

\section{Animals}

Animal experiments were performed in accordance with the regulation set by the institutional committee for the care and use of laboratory animals, and were approved by the local authorities. Sprague-Dawley rats were housed for 21-28 days on a $12 \mathrm{~h} \mathrm{light/dark}$ cycle, and were allowed free access to food and water.

In this study, 45 healthy Sprague-Dawley rats weighing $200 \pm 20 \mathrm{~g}$ (Shilaite Lab.) were used. These rats were kept in individual cage and received standard rat's pellets (Veterinary Institute, China) and water. All rats were allowed to adapt to their new living conditions for one week prior to catheter insertion. During the study period of six weeks, daily behavior of animals was recorded carefully. The parameters included body mass, body temperature, food intake, urine volume, infection, and antibiotics administration (when necessary).

Rats were divided into three groups. Group 1 (G1) $(n=15)$ received daily peritoneal injection through the catheter connected to the abdominal cavity, using peritoneal dialysis solution contain $3.86 \%$ D-glucose (Baxter China). Group 2 (G2) (n=15) received daily peritoneal injection of $0.9 \%$ physiological saline through a catheter. Group $3(\mathrm{n}=15)$ was subjected to sham operation and served as a control.

\section{Anesthesia procedure}

Rats were anesthetized according to the existing protocol which was adapted during the study. Before catheter implantation and sham operation, rats were anesthetized with intraperitoneal injection of chloraldurate (300 $\mathrm{mg} / \mathrm{kg} \quad$ b.w.). This dose of chloraldurate was sufficient for adequate catheter implantation showing no obvious adverse effects on the rats. The majority of rats were anesthetized in $3 \mathrm{~min}$ and remained in the anesthesia for $2 \mathrm{~h}$.

\section{Catheter implantation}

When anesthetized, the rats were shaved on the back of the neck between the ears and scapulae, as well as on the right back or left back under the arcus costarum. The surgical field was prepared in a standard way. Using an aseptic technique, a $2 \mathrm{~cm}$ longitudinal incision in the skin of the left or right back, $1 \mathrm{~cm}$ below the arcus costarum and $1 \mathrm{~cm}$ lateral to the spinal column was made 


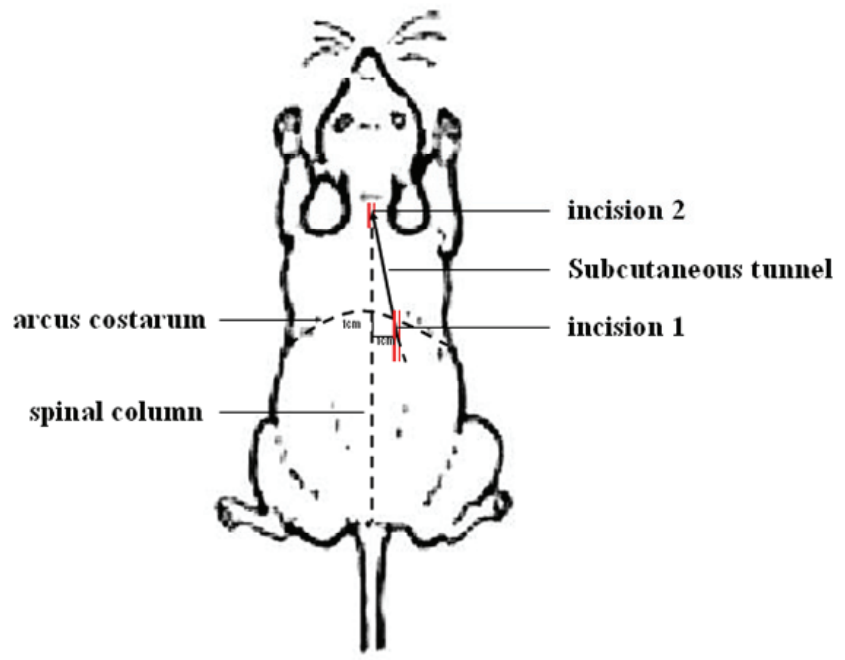

Fig. 2. The description of our model.

(incision 1). A blunt dissection of this area was performed till to the retroperitoneal membrane. Then the catheter tip was inserted into the peritoneal cavity and secured with a purse stitch using suture 4-0 to fix the catheter well. Another $1 \mathrm{~cm}$ longitudinal incision was made in the skin of the posterior neck between two ears (incision 2, Fig. 2). Before closing the skin of the back, $10 \mathrm{ml} 0.9 \%$ physiological saline was administered via the iodophor cap to the catheter to check all possibility of leakage .Then the skin overlying the back was sewed up with single sutures. The catheter was exteriorized through the incision of neck, and the skin was sewed up using suture silk on the catheter. The tresis vulnus was treated and the skin was sewed with traditional methods. Finally, $1 \mathrm{ml}$ of $0.9 \%$ physiological saline containing $5 \mathrm{mg}$ of cefazolin was administered via the iodophor cap to the catheter, followed by $1 \mathrm{ml}$ containing $10 \mathrm{IU}$ of heparin (daily for one week) in order to prevent infection and blockage of catheter (Figure 2).

\section{Sham-operation}

Using the same procedure as mentioned above, the sham-operation group was performed. After these incisions were sewed up without catheter inserting, $5 \mathrm{mg}$ of cefazolin was given by intramuscular injection for one week.

The animals were returned to individual cages and carefully monitored until recovery. Every day the rats were checked the wound and sterilized the external iodophor cap. Each animal was examined for wound dehiscence, iodophor cap breakage, weight loss, or abnormal movement.

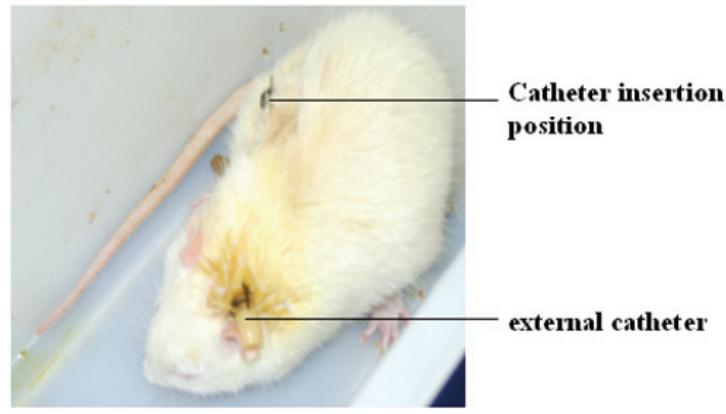

\section{Dialysis procedure}

One week after catheter insertion, either $20 \mathrm{ml}$ of preheated PD solution containing $3.86 \%$ D-glucose or $0.9 \%$ physiological saline was instilled into the catheter using 23 needle with syringe. Instillation was continued daily for 6 weeks. To prevent respiratory problems caused by large amounts of fluid, the solution should be injected slowly. In order to avoid catheter blockage, the catheter was heparinized with daily injection of $10 \mathrm{IU}$ heparin in $1 \mathrm{ml} 0.9 \%$ physiological saline after instillation of PD solution. The solutions were drained out on 2nd, 4th and 6th week, respectively.

\section{Cell count and bacterial presence}

After 2, 4 or 6 weeks of daily injections in G1 and G2 groups, $20 \mathrm{ml}$ of $0.9 \%$ physiological saline solution was injected through catheter. After anesthesia, the control group was injected intraperitoneally through 23 needle in the inferior belly under sterile conditions. After $10 \mathrm{~min}$, solution was drained through catheter in G1 and G2 groups using sterile technique. In control group residual peritoneal fluid was obtained from an incision that was made in the midline of the abdominal wall. After this, the incision was sewed up. The obtained peritoneal fluid was collected for cell count. The episodes of infection, defined as a positive dialysate culture and a dialysate with white blood cell count over $1000 / \mathrm{mm}^{3}$, were diagnosed (De Vriese et al. 2002, Mortier et al. 2004).

\section{Tissue collection}

At the end of the study, the rat was euthanized with an overdose of pentobarbital sodium, and three 
Table 1. Rats general characteristics.

\begin{tabular}{cccccccc}
\hline Group & $\begin{array}{c}\text { Total } \\
\text { number }\end{array}$ & $\begin{array}{c}\text { Excluded } \\
\text { number }\end{array}$ & $\begin{array}{c}\text { Analyzed } \\
\text { number }\end{array}$ & 0 week & 2 weeks & 4 weeks & 6 weeks \\
\hline G1 & 15 & 2 & 13 & $187.3 \pm 2.7$ & $234.1 \pm 3.7$ & $268.0 \pm 5.6$ & $289.9 \pm 6.2$ \\
G2 & 15 & 2 & 13 & $184.6 \pm 5.3$ & $229.4 \pm 6.1$ & $267.8 \pm 3.1$ & $292.9 \pm 2.5$ \\
Control & 15 & 1 & 14 & $183.8 \pm 4.5$ & $236.9 \pm 5.1$ & $271.0 \pm 6.3$ & $296.0 \pm 5.8$ \\
\hline
\end{tabular}

Values are means \pm S.E.M.
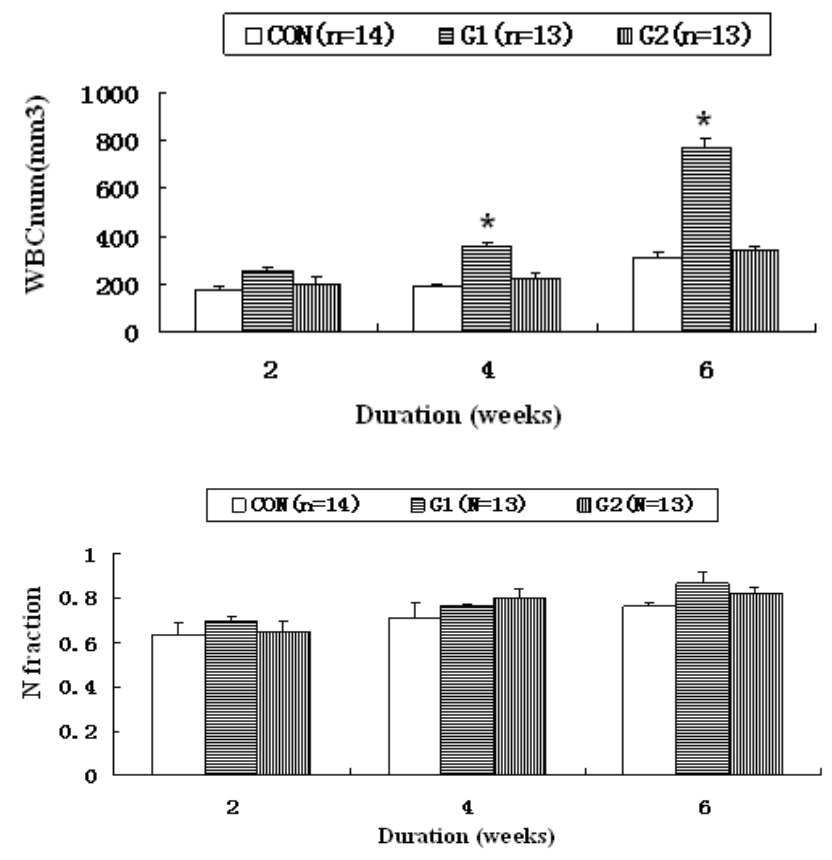

Fig. 3. Total white blood cell (WBC) count and the fraction of neutrophils in each WBC for particular groups at different duration of the experiment. Total white blood cells count is given per $\mathrm{mm}^{3}$ of the peritoneal fluid. Data are mean values \pm S.E.M. Significant differences: * $(p<0.01)$ from control and $G 2$ groups.

different part of abdominal wall samples were collected, about $2 \times 2 \mathrm{~cm}$ in size. The abdominal wall was excised and immediately fixed in neutral pH-buffered $4 \%$ formalin solution for histological analysis. When abdominal wall was cut by surgical scissors, the movement was done gently avoiding tough stretch.

\section{Histology and image analysis}

Tissue was dehydrated, embedded in paraffin, and $5-\mu \mathrm{m}$ sections were cut. Sections were stained with standard hematoxylin-eosin and Masson's trichrome. Peritoneal thickness was quantified in two ways: 1) by measuring the distance from an intact mesothelium to the muscle at five random locations on each slide, and 2) by measuring the thickest span of peritoneum on each slide (Flessner et al. 2006). These measurements were performed by three independent observers with a calibrated optical micrometer and light microscopy (Nikon Eclipse).

\section{Statistical analysis}

Statistical analysis of our data was made using Spss 17.0 and Microsoft Office Excel 2003. Results were presented as mean \pm SEM. Statistical significance between multiple groups was tested with the KruskalWallis test. Individual groups were subsequently tested using the Wilcoxon-Mann-Whitney test. $P<0.05$ value was considered as significant.

\section{Results}

\section{General characteristics of the rats}

Forty-five rats were enrolled in the study. During the experiment lasting 6 weeks, 5 out of 45 rats were left out from this study. Two rats were excluded due to serious infection in G1 group. In addition, one rat had the catheter blocked and one rat died from operation injury in Group 2. In control group, one rat died in anesthesia. On the other hand, at the end of the study, white biofilms were found on the catheters surface in three rats, but catheters were not obstructed completely.

There was no significant difference among three groups in initial body weight and weight changes. All of the rats gained weight during the experimental period (Table 1).

\section{WBC count of peritoneal effluent}

On week 2, white blood cell (WBC) counts of peritoneal effluent in $\mathrm{G} 1$ group were a little higher than those of control group and G2 group, but there were no statistically significant differences (Fig. 3). WBC counts in G1 group were higher than in G2 group and control 
group on weeks 4 and 6 , respectively ( $p>0.01$ ). However, there was no episode of infection in any group. In addition, the fractions of neutrophils were greater in G1 group than in control and G2 groups, but the differences were not statistically significant (Fig. 3).

\section{$\square$ random measurement maximum thickness}
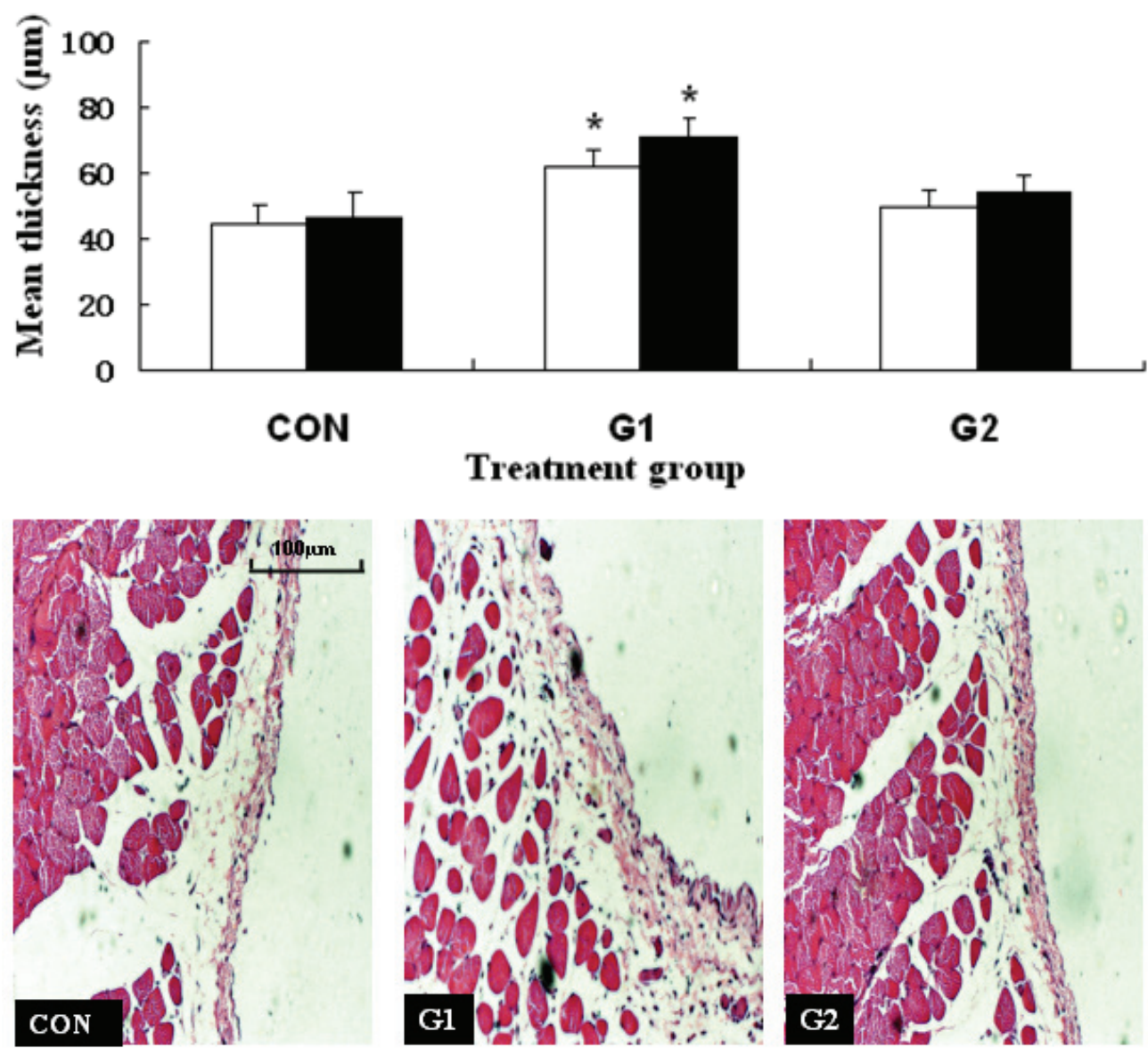

\section{HE $\times 200$}
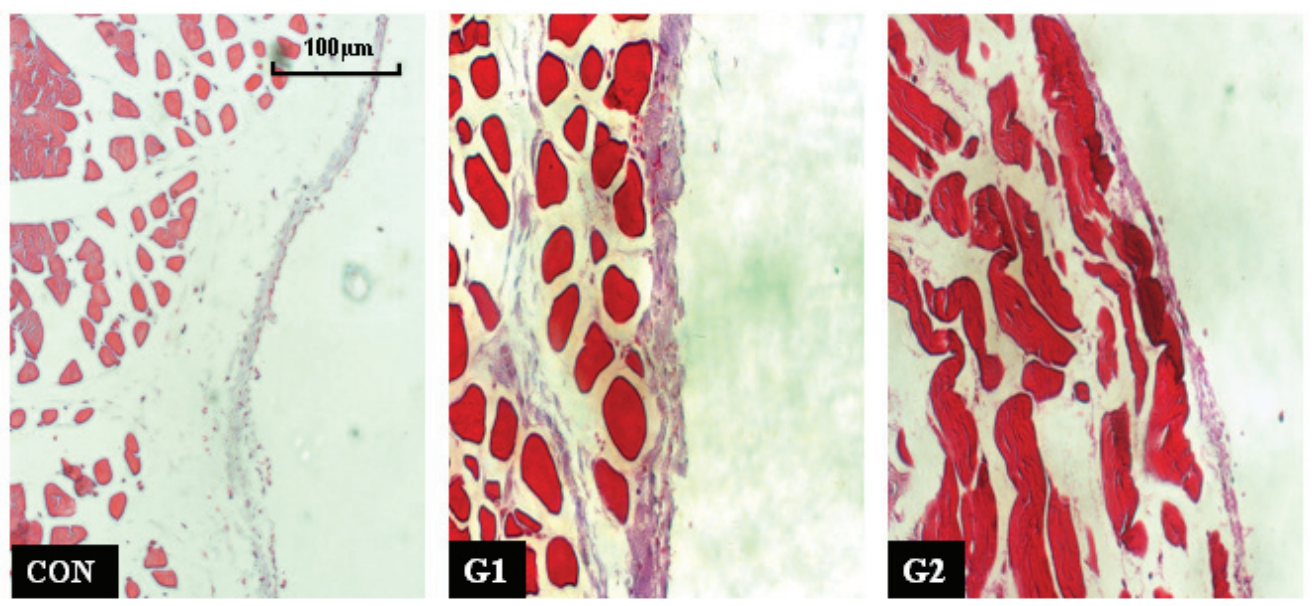

MASSON $\times 200$

Fig. 4. Peritoneal thickness $(\mu \mathrm{m})$ in particular experimental groups. The mean thickness for the $\mathrm{G} 1$ group was significantly different from the control group and $\mathrm{G} 2$ group $(* p<0.01)$. Open bars are derived from five random measurements in each section, and filled bars are derived from the points of maximum thickness. Comparison of peritoneal thickness $(\mu \mathrm{m})(\mathrm{HE} \times 200) ;$ bar $=100 \mu \mathrm{m}$. Comparison of peritoneal thickness $(\mu \mathrm{m})($ MASSON $\times 200) ;$ bar $=100 \mu \mathrm{m}$. 


\section{Histological changes}

As shown in Figure 4, hematoxylin-eosin and Masson's trichrome staining showed significant changes in the thickness of mesothelium-to-muscle layer of peritoneum exposed to high glucose (G1 group) compared to $\mathrm{G} 2$ and control groups. The mean thickness of submesothelial compact zone for G1 group was dramatically increased compared to those of G2 and control groups $(p<0.05)$. There is no difference of submesothelial thickness between G2 and control groups.

\section{Discussion}

Animal models play a key role in understanding alterations in the function and structure of peritoneal tissues during peritoneal dialysis. The functional damage and structural changes of peritoneal membrane are associated with the uremic changes and long-term exposure to PD fluid. Beside these factors, it was demonstrated that silicone catheter widely used peritoneal cavity may induce inflammatory response on peritoneum (Flessner et al. 2007). A traditional PD animal model using a permanent catheter tunneled from the peritoneal cavity and connected to a subcutaneous chamber has some disadvantages, such as a difficult drainage of the dialysate and the need of anesthesia every time when dialysis solution was administered (Mortier et al. 2004, Flessner et al. 2006). In addition, the use of anesthetics can influence peritoneal permeability and kinetics of peritoneal transport by the effect on lymph drainage (Tran et al. 1993). On the other hand, direct intraperitoneal injection used in various PD model can cause infection, trauma to peritoneal tissue, or bowel perforation due to repeated punctures (Gonzalez-Mateo et al. 2008, Flessner et al. 2007, Peng WX et al. 2000).

Since traditional peritoneal catheters caused several common complications (including infection, catheter loss and damage, long external branch irritating the animals), we developed a new non-uremic rat model of PD with a catheter, which adequately imitates the process of $\mathrm{PD}$ in human patients, and provides an important information for studying the structure and physiology of peritoneal membrane in PD.

In this experiment, we modified the catheter insertion method and constructed a new rat model, which showed no catheter pulling out and low infection incidence (Fig. 3). Because the rate of the catheter pull out was very high without additional measures in traditional PD animal model, the added suture fixed on the catheter was used to avoid catheter dropping off (Fig. 2). The dacron cuff on the catheter promoted tissue growth, which can prevent bacterial spread via catheter surface. The iodophor cap used for injection and drainage was more convenient than subcutaneous chamber for subcutaneous injection.

Other serious technical failures in animal models of long-term PD are frequent obstructions of peritoneal access and concomitant infection. The initial step in the formation of catheter-associated biofilm is the adherence of free-floating microorganisms to the catheter surface. This occurs through cell wall-associated adhesions, such as microbial surface components recognizing adhesive matrix molecules, and is facilitated by the deposition of a conditioning film of fibrin and fibronectin on the catheter surface (Trautner et al. 2004, Aslam et al. 2008). Heparin was used to minimize the formation of biofilm because heparin inhibits thrombin and fibrin formation and by virtue of preventing thrombin generation, it can inhibit platelet activation (Niers et al. 2007). In this study, the earliest biofilm formed in three days after catheter implantation was found only in three out of 40 PD rats, which agrees with previously described observations (Zunic-Bozinovski et al. 2008).

Catheters inserted through the abdominal wall into the peritoneal cavity caused a significant inflammatory process in the peritoneum (Flessner et al. 2007). To reduce the direct irritation of peritoneal membrane, in this study the catheter was inserted through the back wall (Fig. 2). This approach resulted in minor structural alterations in the peritoneum. We can therefore hypothesize that the catheter implanted through back wall rather than through abdominal wall may minimize its effects on the peritoneum.

The thickness of submesothelial tissue notably increased as detected by hematoxylin-eosin and Masson staining in rats, which were instilled with $3.86 \%$ D-glucose via a modified catheter. The thickness of peritoneal tissues was significantly increased in G1 group compared to G2 and control groups (Fig. 4), suggesting successful development of a long-term PD animal model.

In this study, we found that the surgical treatment on rat PD model was easily performed and the surgical wound was minor. Complications such as peritonitis, catheter damage or catheter obstruction were negligible using the method introduced in this study. It indicated that this new non-uremic rat model with modified catheter insertion method can be used to analyze the effects of peritoneal dialysis on rat peritoneum with minor structural alterations caused by 
catheter compared to traditional method used in other PD animal models.

\section{Conflict of Interest}

There is no conflict of interest.

\section{Acknowledgements}

This work was supported by the grants of Natural Science of China (C140405. 30971379) and the Ministry of Health Clinical key projects to Fu-You Liu.

\section{References}

ASLAM S: Effect of antibacterials on biofilms. Am J Infect Control 36: S175.e9-S175.e11, 2008.

BOULANGER E, GROSSIN N, WAUTIER MP, TAAMMA R, WAUTIER JL: Mesothelial rage activation by ages enhances VEGF release and potentiates capillary tube formation. Kidney Int 71: 126-133, 2007.

COMBET S, FERRIER ML, VAN LANDSCHOOT M, STOENOIU M, MOULIN P, MIYATA T, LAMEIRE N, DEVUYST O: Chronic uremia induces permeability changes, increased nitric oxide synthase expression, and structural modifications in the peritoneum. J Am Soc Nephrol 12: 2146-2157, 2001.

DE VRIESE AS, TILTON RG, MORTIER S, LAMEIRE NH: Myofibroblast transdifferentiation of mesothelial cells is mediated by rage and contributes to peritoneal fibrosis in uraemia. Nephrol Dial Transplant 21: 2549-2555, 2006.

DE VRIESE AS, MORTIER S, CORNELISSEN M, PALMANS E, VANACKER NJ, LEYSSENS A, FAICT D, DE RIDDER L, LAMEIRE NH: The effects of heparin administration in an animal model of chronic peritoneal dialysate exposure. Perit Dial Int 22: 566-572, 2002.

FLESSNER MF, CHOI J, VANPELT H, HE Z, CREDIT K, HENEGAR J, HUGHSON M: Correlating structure with solute and water transport in a chronic model of peritoneal inflammation. Am J Physiol Renal Physiol 290: F232-F240, 2006.

FLESSNER MF, CREDIT K, HENDERSON K, VANPELT HM, POTTER R, HE Z, HENEGAR J, ROBERT B: Peritoneal changes after exposure to sterile solutions by catheter. J Am Soc Nephrol 18: 2294-2302, 2007.

GONZALEZ-MATEO GT, LOUREIRO-ALVAREZ J, RAYEGO-MATEOS S, RUIZ-ORTEGA M, LOPEZCABRERA M, SELGAS R, AROEIRA LS: Animal models of peritoneal dialysis: relevance, difficulties, and future. (in Spanish) Nefrologia 28 (Suppl 6): 17-22, 2008.

KIHM LP, WIBISONO D, MULLER-KREBS S, PFISTERER F, MORATH C, GROSS ML, SEREGIN Y, BIERHAUS A, NAWROTH PP, ZEIER M, SCHWENGER V: Rage expression in the human peritoneal membrane. Nephrol Dial Transplant 23: 3302-3306, 2008.

MCINTYRE CW: Update on peritoneal dialysis solutions. Kidney Int 71: 486-490, 2007.

MORTIER S, DE VRIESE AS, LAMEIRE N: Recent concepts in the molecular biology of the peritoneal membrane implications for more biocompatible dialysis solutions. Blood Purif 21: 14-23, 2003.

MORTIER S, FAICT D, SCHALKWIJK CG, LAMEIRE NH, DE VRIESE AS: Long-term exposure to new peritoneal dialysis solutions: Effects on the peritoneal membrane. Kidney Int 66: 1257-1265, 2004.

MORTIER S, LAMEIRE NH, DE VRIESE AS: Animal models in peritoneal dialysis research: a need for consensus. Perit Dial Int 25: 16-24, 2005.

NIERS TM, KLERK CP, DINISIO M, VAN NOORDEN CJ, BULLER HR, REITSMA PH, RICHEL DJ: Mechanisms of heparin induced anti-cancer activity in experimental cancer models. Crit Rev Oncol Hematol 61: 195-207, 2007.

OBRADOVIC MM, STOJIMIROVIC BB, TRPINAC DP, MILUTINOVIC DD, OBRADOVIC DI, NESIC VB: Ultrastructural changes of peritoneal lining cells in uremia. Adv Perit Dial 16: 26-30, 2000.

PENG WX, GUO QY, LIU SM, LIU CZ, LINDHOLM B, WANG T: Comparison of three chronic dialysis models. Adv Perit Dial 16: 51-54, 2000.

PLUM J, HERMANN S, FUSSHOLLER A, SCHOENICKE G, DONNER A, ROHRBORN A, GRABENSEE B: Peritoneal sclerosis in peritoneal dialysis patients related to dialysis settings and peritoneal transport properties. Kidney Int Suppl 78: S42-S47, 2001.

TEITELBAUM I, BURKART J: Peritoneal dialysis. Am J Kidney Dis 42: 1082-1096, 2003. 
TOPLEY N: Animal models in peritoneal dialysis: more questions than answers? Perit Dial Int 25: 33-34, 2005.

TRAN L, RODELA H, HAY JB, OREOPOULOS D, JOHNSTON MG: Quantitation of lymphatic drainage of the peritoneal cavity in sheep: comparison of direct cannulation techniques with indirect methods to estimate lymph flow. Perit Dial Int 13: 270-279, 1993.

TRAUTNER BW, DAROUICHE RO: Catheter-associated infections: pathogenesis affects prevention. Arch Intern Med 164: 842-850, 2004.

WILLIAMS JD, CRAIG KJ, TOPLEY N, VON RUHLAND C, FALLON M, NEWMAN GR, MACKENZIE RK, WILLIAMS GT; Peritoneal Biopsy Study Group: Morphologic changes in the peritoneal membrane of patients with renal disease. J Am Soc Nephrol 13: 470-479, 2002.

ZAREIE M, DE VRIESE AS, HEKKING LH, TER WEE PM, SCHALKWIJK CG, DRIESPRONG BA, SCHADEEEESTERMANS IL, BEELEN RH, LAMEIRE N, VAN DEN BORN J: Immunopathological changes in a uraemic rat model for peritoneal dialysis. Nephrol Dial Transplant 20: 1350-1361, 2005.

ZUNIC-BOZINOVSKI S, LAUSEVIC Z, KRSTIC S, JOVANOVIC N, TRBOJEVIC-STANKOVIC J, STOJIMIROVIC B: An experimental, non-uremic rabbit model of peritoneal dialysis. Physiol Res 57: 253260, 2008. 